\title{
Design method and application of accurate adjustment scheme for water injection wells around adjustment wells
}

\author{
Tongchun Hao ${ }^{1}$ (1) - Liguo Zhong ${ }^{1}$. Jianbin Liu ${ }^{1}$ Xiaodong Han ${ }^{1,2}$ - Tianyin Zhu ${ }^{1}$ Xiaocheng Zhang ${ }^{2}$. \\ Xiaopeng Wang ${ }^{2} \cdot$ Lei Zhang $^{2}$
}

Received: 30 August 2021 / Accepted: 8 October 2021 / Published online: 8 November 2021

(c) The Author(s) 2021

\begin{abstract}
Affected by the surrounding injection and production wells, the formation near the infill adjustment well is in an abnormal pressure state, and drilling and completion operations are prone to complex situations and accidents such as leakage and overflow. The conventional shut-in method is to close all water injection wells around the adjustment well to ensure the safety of the operation, but at the same time reduce the oil field production. This paper proposes a design method for shut-in of water injection wells around adjustment wells based on injection-production data mining. This method uses water injection index and liquid productivity index as target parameters to analyze the correlation between injection and production wells. Select water injection wells with a high correlation and combine other parameters such as wellhead pressure and pressure recovery speed to design accurate adjustment schemes. Low-correlation wells do not take shut-in measures. This method was applied to 20 infill adjustment wells in the Penglai Oilfield. The correlation between injection and production wells was calculated using the data more than 500 injection wells and production wells. After a single adjustment well is drilled, the surrounding injection wells can increase the water injection volume by more than $5000 \mathrm{~m}^{3}$. This method achieves accurate adjustment for water injection wells that are high correlated with the adjustment well. Under the premise of ensuring the safety of drilling operations, the impact of drilling and completion on oilfield development is minimized, and oilfield production efficiency is improved. It has good application and promotion value.
\end{abstract}

Keywords Data mining $\cdot$ Adjustment well $\cdot$ Pressure control $\cdot$ Accurate shut-in

\section{Introduction}

In the process of oilfield waterflooding development, the efficiency of oilfield development and benefit of oilfield decreased due to factors such as invalid water injection cycle and formation damage after the high-permeability channel broke through the water (Rui et al. 2017a,b, 2018a, b). The pressure field and flow field can be re-adjusted through well pattern densification (Zhang et al. 2011; Jiang et al. 2011), hydraulic fracturing (Rui et al. 2018a, b) and acid fracturing (Guo et al. 2018a, b) to increase the scope of water injection, use remaining oil, and improve oilfield recovery. However,

Liguo Zhong

Zhongliguo007@163.com

1 China University of Petroleum (Beijing), Beijing 102249, China

2 China National Offshore Oil Corporation China Ltd., Tianjin Branch, Tianjin 300459, China during the drilling and completion of the infill adjustment well, affected by the surrounding geological conditions and injection-production wells, the formation pressure near the adjustment well may be in an overpressure or underpressure state, leading to complicated situations and accidents such as leakage and overflow. This can be seen from the pressure measurement while drilling data (Ma et al. 2018; Peng et al. 2021) (Fig. 1). In order to adjust the formation pressure and reduce the operation risk, the surrounding injectionproduction wells or the daily injection-production rate can be adjusted: the conventional method is to close all injection wells around the adjustment well to ensure the safety of the operation. However, the conventional adjustment method seriously affects the production progress of the oil field, and it may cause irreversible damage to the formation while changing the production system. For this reason, this article puts forward the idea of accurate adjustment: only adjust individual water injection wells, and close water injection 

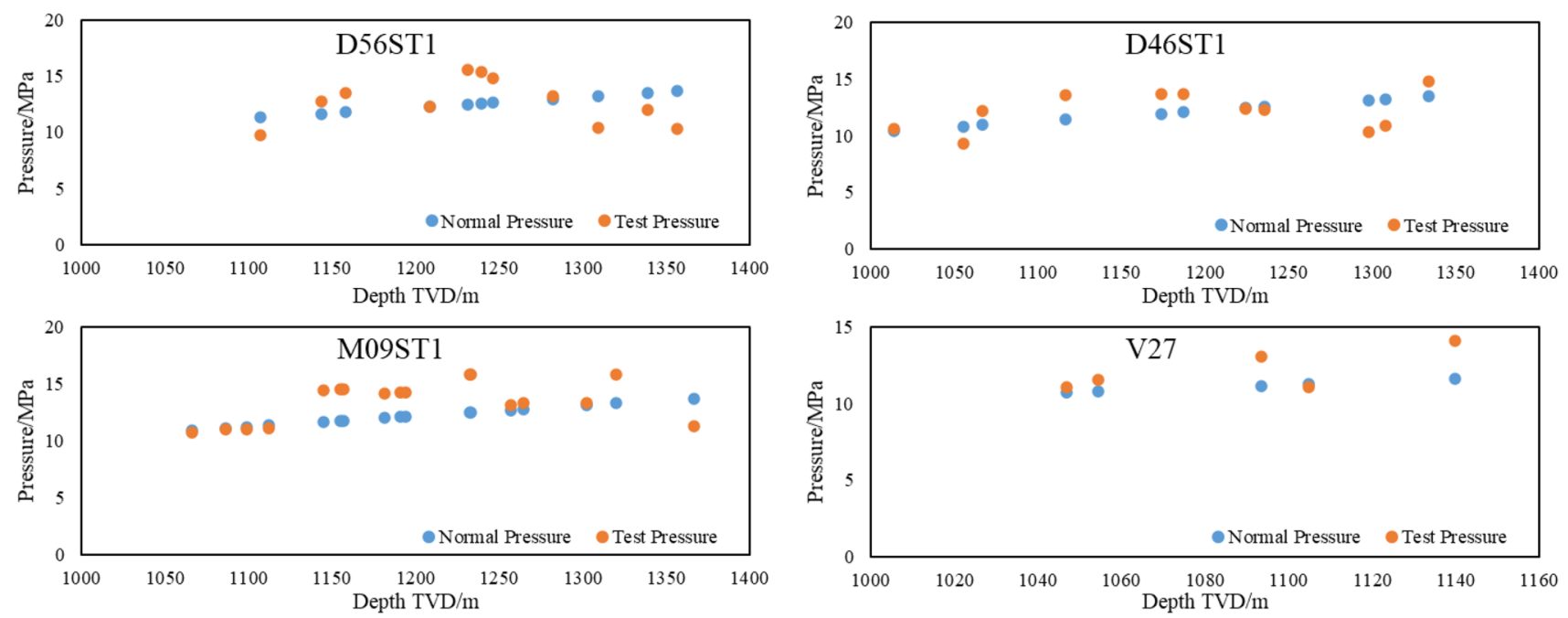

Fig. 1 Pressure measurement while drilling data of adjusting wells in bohai oilfield

wells as little as possible on the premise of ensuring the safety of drilling and completion operations.

Accurately predicting the source of abnormal formation pressure is a prerequisite for accurate adjustment. Radwan et al. (2019), Li et al. (2019), Wang et al. (2011) established numerical calculation methods to calculate formation pressure by using logging data, well history data, and geological data. Liu and Wang (2003) calculated the diffusion equation reflecting the law of underground seepage by using finite element method on the basis of making use of the local pressure data and production dynamic data of injection wells and production wells. Yao et al $(2001,2009)$ established a fine reservoir geological model and obtained accurate current formation pressure distribution through history matching. Feng et al. (2017), Xu et al. (2018), Zhu et al. (2011) used the numerical simulation theory of the reservoir to analyze the change of pore pressure of the reservoir by using the dynamic and static parameters of the oilfield production and established a set of basic feasible theory and method for adjusting the formation pressure of the wells. Prediction of formation pore pressure and collapse pressure are used as an important basis for determining wellbore structure and drilling fluid density. However, the above formation pressure analysis methods require a large amount of field test data, the analysis methods are complex, and the accuracy of prediction depends on the accuracy of the data, which is not generalizable. Therefore, it is necessary to infer the source of abnormal formation pressure by analyzing the correlation of injection-production wells. In the existing technology (Vaferi et al. 2012; Liu et al. 2009; Wang et al. 2021; Xie et al. 2017; Yousef et al. 2006; Zhao et al. 2008; Zhao et al. 2017; Zhao et al. 2016), the correlation between injection wells and production wells is usually determined according to the injection volume and the production volume. The reservoir is regarded as a system characterized by continuous impulse response. It is a process of generating an output signal (liquid production rate) from an input signal (water injection rate). The reservoir model can be built into a resistance model represented by weights, a capacitance model or a capacitance-resistance model characterized by parameters representing inter-well connectivity and dissipation. Inter-well connectivity can be quantitatively estimated by multi-linear regression of model parameters. However, the correlation analysis results obtained by this method fluctuate greatly and have low accuracy, which affects the effect of reservoir reform measures such as profile adjustment of injection wells, plugging of production wells, and acid fracturing.

Therefore, based on previous scholars' research, this paper proposes a more suitable method for field application of correlation analysis of injection and production well. The method is suitable for medium- and high-permeability reservoirs developed by water flooding. In order to modify the influence of formation pressure on the results, water injection index and liquid productivity index are introduced as the research objects. After determining the water injection wells with high correlation with the adjustment wells, the production parameters of the water injection wells are combined to formulate a precise adjustment plan (Fig. 2). Under the premise of ensuring the safety of drilling operations, the use of precise shut-in adjustments instead of conventional shut-in measures minimizes the impact of adjustment drilling and completions on oilfield development and improves oil production efficiency. 


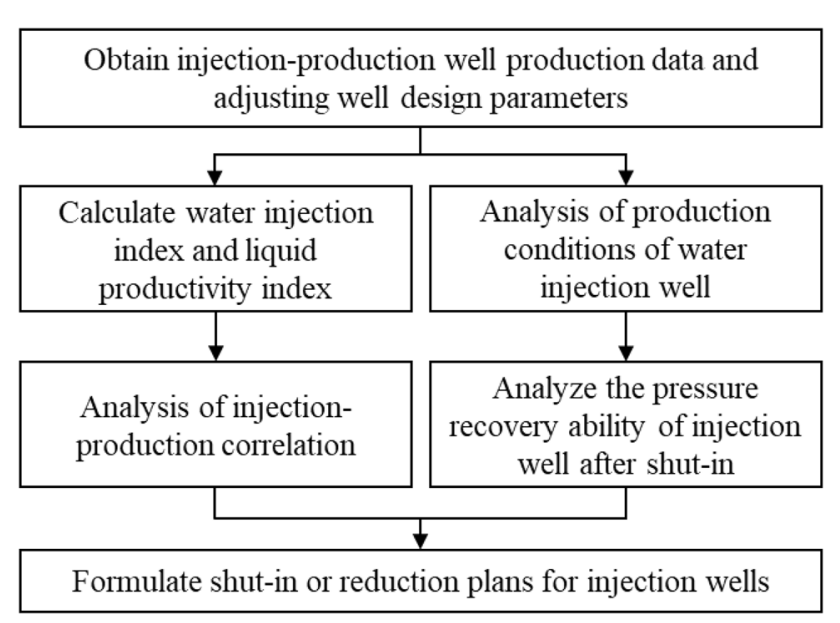

Fig. 2 Flow chart of design of accurate adjustment scheme for water injection well

\section{Research methods}

\section{Injector-producer relationships}

The degree of influence on the formation pressure change after the shut-in of the injection well around the adjustment well is affected by many factors. The research methods of using permeability, crude oil viscosity, well spacing, and well pattern to determine whether the injection well needs to be closed are too complicated and difficult. Therefore, a correlation analysis method of injection-production was introduced to determine the degree of influence of the injection well on the formation pressure of the adjustment well. It is judged whether the injection well needs to be closed according to the size of the correlation between injection and production.

Yousef et al. (2006) deduced the fluid production equations of the production well at time $t$ by combining the conservation equation of matter and the liquid productivity index:
Equation 1 has strong physical significance, but it is difficult to be generalized in application due to its complex parameters and solving process. This paper proposes to simplify the calculation of the response function between injection and production wells with clear physical meaning and retain the characteristics of the response function to the greatest extent.

The first item on the right side of the Eq. (1) is the response production obtained from the initial output in response to the unit rectangular pulse signal. The second term is the response production provided by the injection well from the initial time to time $t$. The third item is the response production caused by the change in bottom hole pressure. Where $\tau=\frac{c_{t} \nu_{p}}{J}$ is a parameter composed of aggregate elasticity compressibility, pore volume, and liquid productivity index, which can reflect the geological conditions between injection and production wells. Therefore, it can be expressed as a response function parameter to control the contribution of water injection to liquid production.

The second item of water injection response value in Eq. (1) is simplified as:

$\mathrm{h}_{1}(t)=a e^{-a t}$

The fluid production equations of the production well is

$q(t)=h_{1}(t) * i(t)=\sum_{n-1}^{t-1} a e^{-a(t-n)} i(n)$.

* is the convolution function operation symbol. The production rate of the production well at time $t$ is equal to the sum of the response values of all water injections at time $n=1,2,3, \ldots, t$ under the $h_{1}(t)$ response function. A discrete diagram of the unit impulse after the response function $h_{1}(t)$ is shown in Fig. 3. Figure 3a shows the response at time $t$ after the injection signal occurs. As the response time increases, the response value decreases, which is consistent with the law of energy loss in the formation

$q(t)=q\left(t_{0}\right) e^{\frac{-\left(t-t_{0}\right)}{\tau}}+\frac{e^{\frac{-t}{\tau}}}{\tau} \int_{\xi=t_{0}}^{\xi=t} e^{\frac{\xi}{\tau}} i(\xi) \mathrm{d} \xi+J\left[P_{w f}\left(t_{0}\right) e^{\frac{-\left(t-t_{0}\right)}{\tau}}-P_{w f}(t)+\frac{e^{\frac{-t}{\tau}}}{\tau} \int_{\xi=t_{0}}^{\xi=t} e^{\frac{\xi}{\tau}} P_{w f}(\xi) \mathrm{d} \xi\right]$,

Fig. 3 Discrete diagram of the response function with a monotonic decreasing function

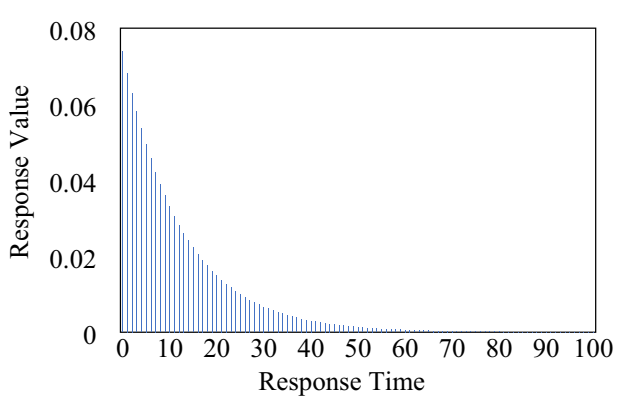

(a)

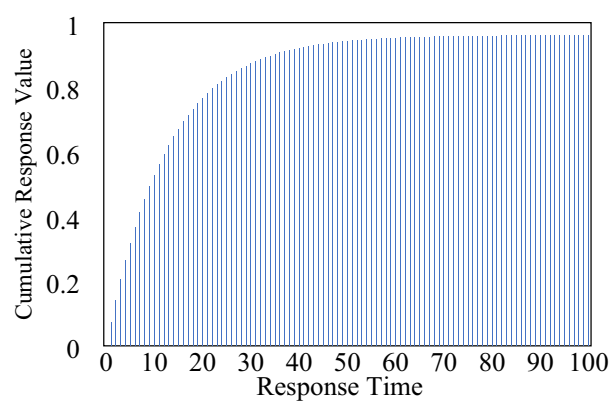

(b) 
in reservoir engineering. Figure $3 \mathrm{~b}$ shows the sum of all responses $n \in(0, t)$ after the injection signal occurs. Under the unit pulse condition, the maximum cumulative response is still less than 1 . In reservoir engineering, owing to the differences in oil-water volume coefficients caused by the differences in oil-water density and the ability to accumulate fluid in the reservoir, the liquid production of production wells is often lower than the water injection of water injection wells.

Figure 4 shows the distribution of the response value and cumulative response value when the response parameter $a$ changes. Figure 4 also shows that the value of $a$ has two effects on the response: (1) It affects the size of the response. When the value of $a$ is smaller, the maximum value of the response is also smaller. (2) It affects the size of the cumulative response. When the value of $a$ is smaller, the maximum value of the cumulative response is also smaller. Similarly, in reservoir engineering, when the relationship between injection and production wells is poor, the response value of the daily water injection is small, and the contribution of water injection wells to the production well fluid production is low.

The response function has definite physical meaning, consistent with the production status of injection-production wells in reservoir engineering, and can accurately describe the relationship between the injection rate and production rate. Therefore, this study takes $h_{1}(t)$ as the most optimal response function, and based on this, a correlation analysis model of injection and production wells is established.

The IPR between water injectors and producers is defined as the ratio of the water injector's contribution to the liquid production and the water injection rate. Because the injection rate is constant during the step process, the IPR can be expressed as

$\operatorname{IPR}=\frac{q(t)}{i(t)}=\sum_{n=1}^{t-1} a e^{-a(t-n)}=\sum_{n=1}^{t-1} h(t-n)=\left.H(Z)\right|_{(Z=1)}=\frac{a}{1-e^{-a T}}$,

For the first time, Liu et al (2009) combined the extended Kalman filter with the injection-production relationship (IPR) and used the water injection rate and fluid production rate to predict the injection-production relationship. In this paper, the extended Kalman filter algorithm is also used to solve Eq. (4), and the solving process is shown in Fig. 5. And the correlation coefficient $a$ of injection-production well can be obtained through inversion of actual production data.

In the actual calculation process, when the formation permeability decreases, the injection rate of the injection well also decreases, which usually occurs in the early stage of reservoir development. However, in order to improve the development degree and efficiency of the reservoir, measures, such as profile control and water shutoff, layered water injection, and optimized injection and production, are implemented. Water injection and fluid production under such production conditions often do not reflect the relationships within the formation. Bottom hole pressure was used to correct injection-production rate. Therefore, water injection index and liquid productivity index are used to calculate. Water injection index is the water injection speed under unit pressure difference. It reflects the actual water injection volume of the injection well, expressed as

$J_{i}=\frac{i}{P_{h}+\left(P_{g}-P_{z}\right)-P_{o}}$

where $J_{i}$ is the water injection index, and $i$ is water injection rates, and $P_{h}$ is wellhead pressure, and $\left(P_{g}-P_{z}\right)$ is the pressure exerted on the bottom hole by fluid gravity and tubing resistance counteracting each other in the wellbore, and $P_{o}$ is mean formation pressure.

The liquid productivity index reflects the true fluid production capacity of the production well and is expressed as

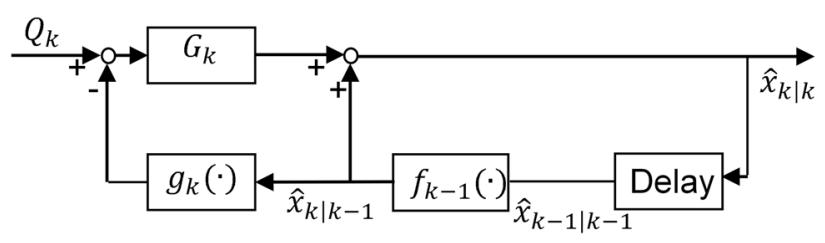

Fig. 5 Schematic diagram of the correction process in the EKF algorithm
Fig. 4 Distribution of responses and cumulative responses with different values of parameter a

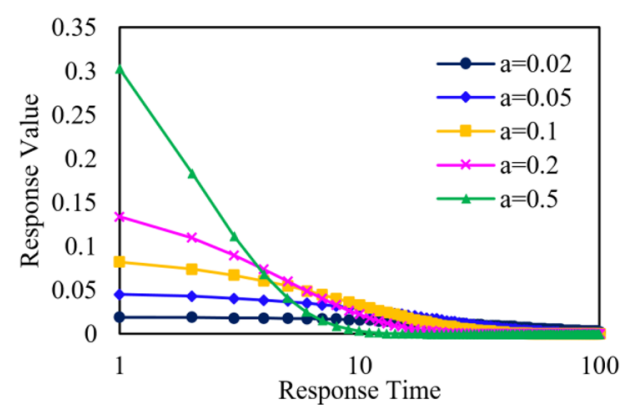

(a)

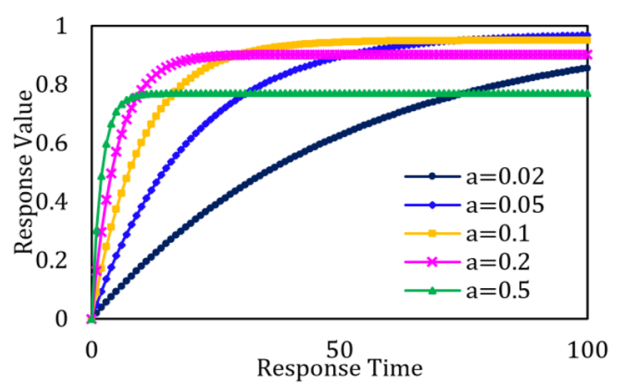

(b) 
$J_{\mathrm{q}}=\frac{q}{P_{o}-P_{w}}$

where $J_{\mathrm{q}}$ is the liquid productivity index, $q$ is fluid production rates, and $P_{w}$ is bottom hole pressure of production well.

\section{Design shut-in scheme}

By calculating the correlation results of all produced wells around the injection well, the area of the produced wells with high correlation with the injection well can be obtained. When the adjustment well is in the high correlation region of the injection well, the injection well is also a high correlation well to the adjustment well. In the high correlation area, the contribution of water injection wells to the water fraction and pressure of the area is higher, which has a great impact on the drilling and completion of the adjustment well, so it is necessary to consider reducing water injection or shutting in the well.

We first carried out field application in Penglai Oilfield in Bohai Sea. Geological conditions of Penglai Oilfield: Penglai 19-3 oil field is located in the South-Central Bohai Sea. The core physical property analysis shows that the Guantao Formation reservoir has a porosity of 13.2-32.6\%, and a permeability of $5.1 \sim 5900 \mathrm{mD}$; the lower member of Minghuazhen formation has a porosity of $12.2-34.7 \%$ and a permeability of $3.4 \sim 2200 \mathrm{mD}$. The reservoir has medium-high porosity and permeability. The reservoir is composed of a normal pressure system and a normal temperature system, with a geothermal gradient of $2.8^{\circ} \mathrm{C} / 100 \mathrm{~m}$, an average pressure gradient of $0.97 \mathrm{MPa} / 100 \mathrm{~m}$, and an average pressure coefficient of 1.03 .

Distribution of water injection wells in Penglai 19-3 oilfield: the Minghuazhen formation of Area 1 is mainly developed by directional wells and partially using horizontal wells, and uses irregular injection-production well patterns. The design well spacing is mainly $200-300 \mathrm{~m}$, the maximum injection-production well spacing is about $320 \mathrm{~m}$, and the minimum injection-production well spacing is about $200 \mathrm{~m}$. The Guantao Formation is divided into two sets of development strata, mainly using directional wells. The row-shaped injection-production well pattern is adopted, and the design well spacing is mainly $250-300 \mathrm{~m}$, the maximum injectionproduction well spacing is about $410 \mathrm{~m}$, and the minimum injection-production well spacing is about $120 \mathrm{~m}$.

Injection rate design of water injection wells: the apparent water injectivity index in meters of the water injection wells in Area 1 of Penglai 19-3 Oilfield is set at $2.4 \mathrm{~m}^{3 /}$ $(\mathrm{MPa} \cdot \mathrm{d} \cdot \mathrm{m})^{-1}$. The water injection rate of a single well is $571-967 \mathrm{~m}^{3} / \mathrm{d}$, with an average of $749 \mathrm{~m}^{3} / \mathrm{d}$.

According to the geological and development characteristics of Bohai oilfield and combined with the field trial shut-in pressure drop, the table of peripheral water injection shut-in regulation system during infill adjustment well drilling and completion operation with different water injection pressures and different well spacing is formulated, as shown in Table 1.

\section{Field application}

Take the adjustment well A in the southern part of Penglai Oilfield as an example. Due to the large number of injection and production wells in this area, the strong reservoir heterogeneity and the imbalance of the total injection and production volume, the adjustment well A is easily affected by surrounding production wells during drilling and completion operations. Table 2 shows the pressure prediction for each layer of adjustment well A. It can be seen that there is a high risk of overpressure in this well. Therefore, it is
Table 1 Design table of water injection well adjustment scheme

\begin{tabular}{|c|c|c|c|}
\hline Distance (m) & $\begin{array}{l}\text { Wellhead pressure } \\
(\mathrm{MPa})\end{array}$ & IPR calculation results & Measures \\
\hline \multirow[t]{2}{*}{$<100$} & $4-11$ & Weak/moderate/strong & 7-10 day/Shut-in \\
\hline & $<4$ & Weak/moderate/strong & 7-10 day/Reduce injection \\
\hline \multirow[t]{6}{*}{$100-300$} & $5-11$ & Strong & 7-10 day/Reduce injection \\
\hline & & Moderate & 3-5 day/Reduce injection \\
\hline & & Weak & 1-3 day/Reduce injection \\
\hline & $<5$ & Strong & 3-5 day/Reduce injection \\
\hline & & Moderate & 1-3 day/Reduce injection \\
\hline & & Weak & No measures \\
\hline \multirow[t]{4}{*}{$300-500$} & $6-11$ & Strong & 3-5 day/Reduce injection \\
\hline & & Moderate & 1-3 day/Reduce injection \\
\hline & & Weak & No measures \\
\hline & $<6$ & Weak/moderate/strong & No measures \\
\hline$>500$ & $0-11$ & Weak/moderate/strong & No measures \\
\hline
\end{tabular}


Table 2 Pressure prediction table for each oil group of adjustment well A

\begin{tabular}{lcccccc}
\hline Layer & MD $(\mathrm{m})$ & TVDss $(\mathrm{m})$ & \multicolumn{2}{l}{ Formation pressure $(\mathrm{MPa})$} & Remark \\
\cline { 3 - 5 } & & & Normal pressure & $\begin{array}{l}\text { Predicted } \\
\text { minimum }\end{array}$ & $\begin{array}{l}\text { Predicted } \\
\text { maximum }\end{array}$ & \\
\hline 1 & 887 & -846 & 8.9 & 8.9 & 8.9 & Normal pressure \\
2 & 915 & -874 & 9.1 & 9.1 & 9.1 & Normal pressure \\
3 & 942 & -901 & 9.4 & 9.4 & 9.7 & Overpressure \\
4 & 978 & -937 & 9.7 & 9.7 & 10.0 & Overpressure \\
5 & 1029 & -988 & 10.2 & 10.6 & 12.5 & Overpressure \\
6 & 1088 & -1047 & 10.7 & 10.7 & 11.5 & Overpressure \\
7 & 1119 & -1078 & 11.0 & 11.0 & 13.0 & Overpressure \\
8 & 1169 & -1128 & 11.5 & 12.1 & 14.0 & Overpressure \\
\hline
\end{tabular}

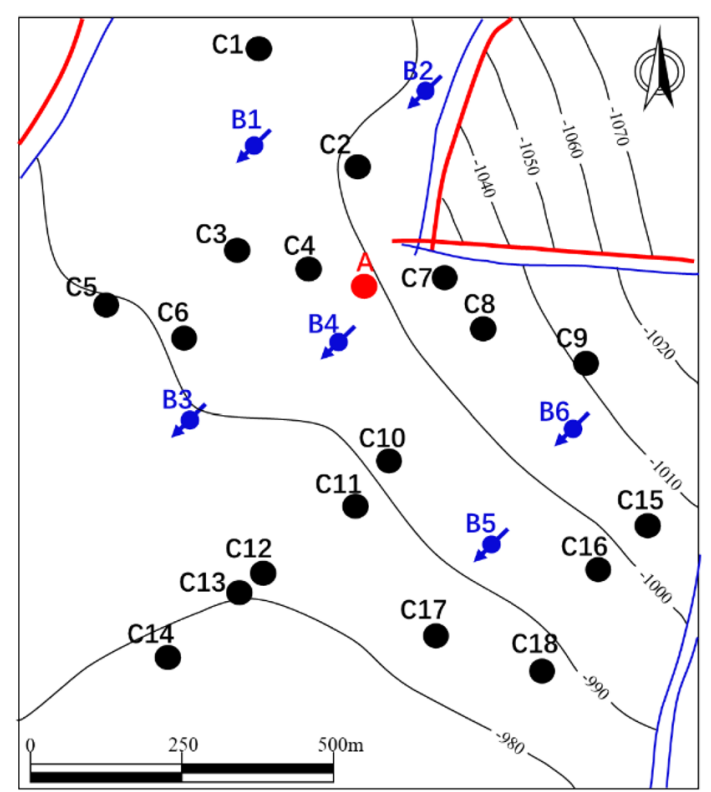

Fig. 6 The well location map of adjustment well A necessary to shut-in or de-inject the wells that are concerned with adjustment well $\mathrm{A}$.

Based on the well location map of adjustment well A (Fig. 6), water injection wells within twice the well spacing around well A are selected for research. According to the flowchart in Fig. 1, first collect the production performance data of each water injection well and analyze the production conditions of each well. Figure 6 shows the production performance curve of each injection well. Figure 7 shows the wellhead pressure recovery curve of each water injection well after shut-in. It can be seen that the pressure recovery speed and degree of each water injection well are different. The wellhead pressure of B6 well can only be reduced to $4 \mathrm{MPa}$ under shut-in conditions, but the wellhead pressure of $\mathrm{B} 1$ well can be reduced to less than $0.5 \mathrm{MPa}$. The reason is that the reservoir conditions of the formation near the water injection well are different. The lower the permeability, the slower the pressure recovery rate. For wells with poor pressure recovery ability, shut-in or de-injection can be performed longer in advance.

Calculate the water injection index and liquid productivity index according to Eqs. (5) and (6) based on the production performance data of each injection-production well.

Use MATLAB calculation software to compile the EKF algorithm solution Eq. (4), import the water injection index
Fig.7 Shut-in pressure drop curve of injection well around adjustment well A

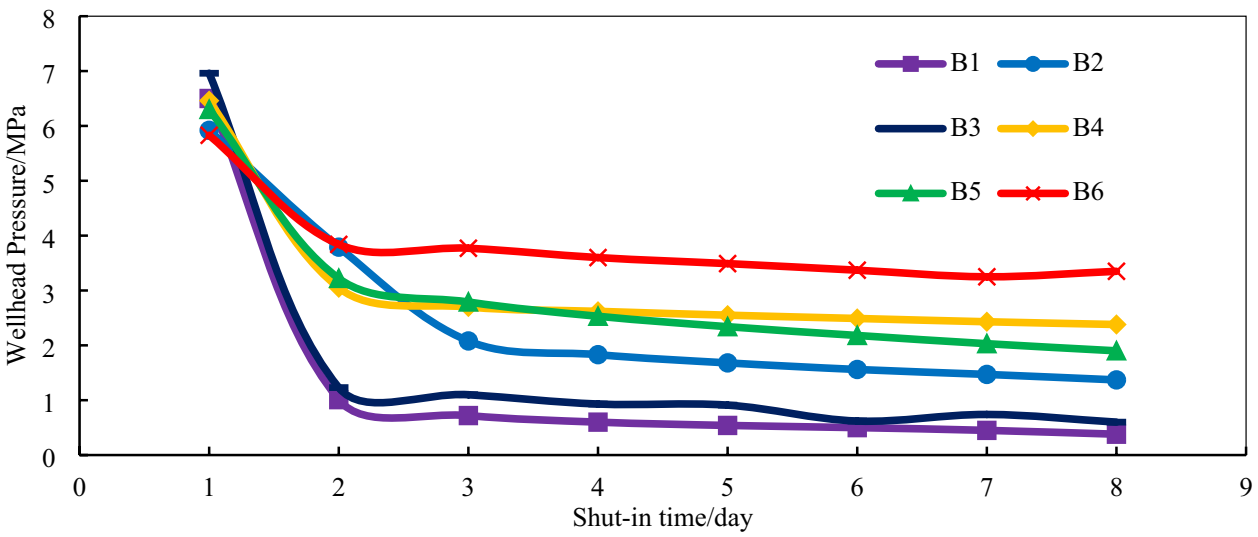


and the liquid productivity index to calculate the correlation between injection and production wells, and get the high correlation area of each water injection well. Table 3 shows the calculation results of each injection-production correlation, which includes only the injection-production wells with strong and medium injection-production correlation, and the wells that are not shown are the wells with weak correlation.

According to IPR calculation results in Table 3, the high correlation area of each injection well can be represented on the well location map (Fig. 8). When the adjustment well $\mathrm{A}$ is located in the high correlation area, the water injection well needs attention. It can be seen from Fig. 8 that adjustment well $\mathrm{A}$ is located in the high correlation area of B1, B2, and B4. Therefore, these water injection wells need attention.

According to the distance between each water injection well and the adjustment well, wellhead pressure, IPR calculation results and pressure recovery speed after shut-in, combined with the water injection well adjustment plan design table in Table 1, the adjustment scheme of each water injection well around adjustment well $\mathrm{A}$ is obtained (Table 4). Among them, wells B1, B2, and B4 need to take injection reduction measures before adjustment well A encounters the target zone, and no measures are taken for other wells.

Adjustment well A adopted the optimization measures in Table 4 during the drilling operation. The construction process went smoothly without any abnormalities. Compared

Table 3 The IPR Calculation Results

\begin{tabular}{lllll}
\hline $\begin{array}{l}\text { Injecting } \\
\text { well }\end{array}$ & $\begin{array}{l}\text { Producing } \\
\text { well }\end{array}$ & IPR & Date & Result \\
\hline B1 & C2 & 0.2621 & $2017.9 .1-2018.9 .1$ & Strong \\
& C3 & 0.2044 & $2017.9 .1-2018.9 .1$ & Moderate \\
& C5 & 0.2008 & $2017.9 .1-2018.9 .1$ & Moderate \\
B2 & C2 & 0.7327 & $2017.9 .1-2018.9 .1$ & Strong \\
B3 & C13 & 0.4157 & $2017.9 .1-2018.9 .1$ & Strong \\
& C12 & 0.1626 & $2017.9 .1-2018.9 .1$ & Strong \\
& C11 & 0.1183 & $2017.9 .1-2018.9 .1$ & Moderate \\
B4 & C11 & 0.2519 & $2017.9 .1-2018.9 .1$ & Strong \\
& C10 & 0.1594 & $2017.9 .1-2018.9 .1$ & Strong \\
& C2 & 0.1280 & $2017.9 .1-2018.9 .1$ & Strong \\
& C8 & 0.1157 & $2017.9 .1-2018.9 .1$ & Strong \\
& C3 & 0.0974 & $2017.9 .1-2018.9 .1$ & Moderate \\
B5 & C17 & 0.2411 & $2017.9 .1-2018.9 .1$ & Strong \\
& C11 & 0.2147 & $2017.9 .1-2018.9 .1$ & Strong \\
& C10 & 0.1370 & $2017.9 .1-2018.9 .1$ & Moderate \\
B6 & C11 & 0.3736 & $2017.9 .1-2018.9 .1$ & Strong \\
& C10 & 0.2323 & $2017.9 .1-2018.9 .1$ & Strong \\
& C8 & 0.1644 & $2017.9 .1-2018.9 .1$ & Strong \\
& C16 & 0.1080 & $2017.9 .1-2018.9 .1$ & Moderate \\
\hline
\end{tabular}

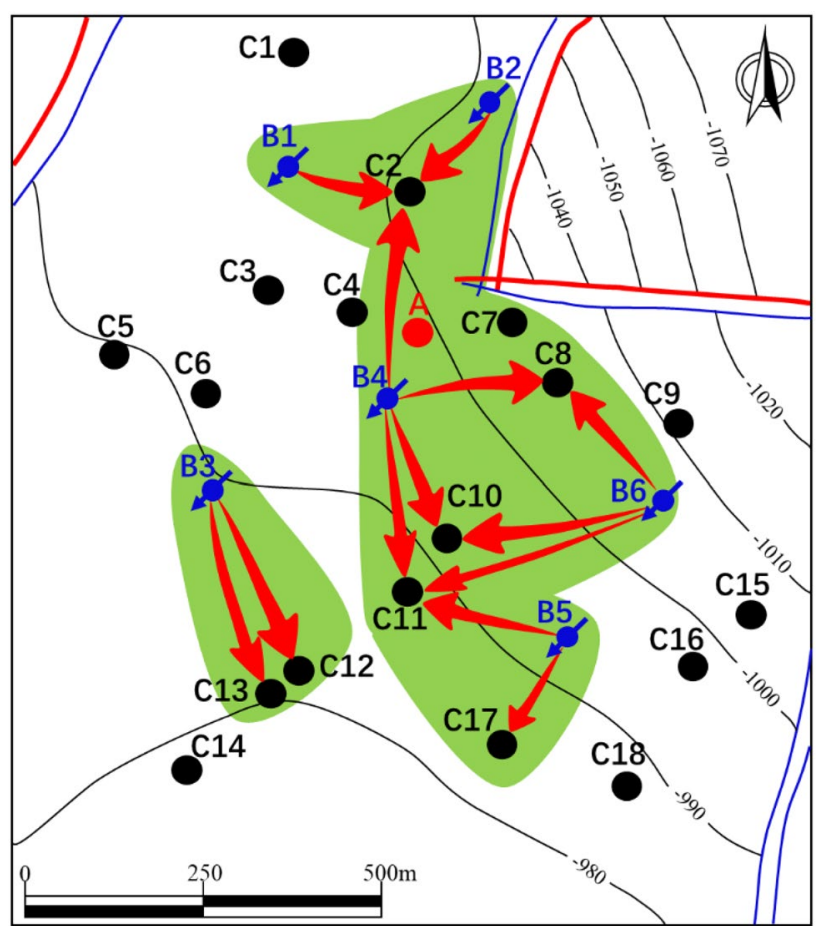

Fig. 8 The high correlation area of each injection well

with traditional measures, the optimized water injection wells injected $5000 \mathrm{~m}^{3}$ more water during the drilling operation of adjustment well A. This is very important in the oilfield development process, which can better maintain the formation pressure and production well production under the premise of ensuring the safety of drilling.

Currently, more than 20 wells have been used in the Bohai Oilfield. The IPR of injection and production wells is calculated by using the water injection index and liquid productivity index of more than 500 groups of injection and production wells. Comparing the calculation results with the geological data, the accuracy of the correlation prediction results of the injection wells reached more than $85 \%$.

The conventional shut-in scheme of "close the well 3 to 15 days in advance within $400-600 \mathrm{~m}$ of the distance adjustment well" is optimized to "reduce injection or shut down the well 3 to 10 days before drilling in the target area according to the injection-production relationship". Not only ensured the safety of offshore drilling, but also greatly reduced the impact on the development of oil fields.

\section{Conclusions}

Judging the influence of injection well on adjusting well pressure is the basis of accurate adjustment. By analyzing the correlation between injection wells and surrounding production wells, the high correlation area of injection wells

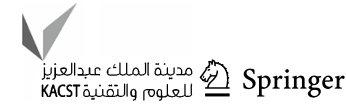


Table 4 The adjustment scheme of each water injection well around the adjustment well

\begin{tabular}{lllllll}
\hline Injection well & Distance $(\mathrm{m})$ & $\begin{array}{l}\text { Wellhead } \\
\text { pressure } \\
(\mathrm{MPa})\end{array}$ & IPR & $\begin{array}{l}\text { Wellhead pressure } \\
\text { recovery rate }\end{array}$ & Conventional measures & Optimization measures \\
\hline B1 & 293 & 6.36 & Strong & Fast & 7 day/Shit in & 7 day/reduce injection \\
B2 & 339 & 6.66 & Strong & Fast & 3 day/Shit in & 3 day/reduce injection \\
B3 & 363 & 6.30 & Weak & Fast & 3 day/Shit in & No measures \\
B4 & 105 & 6.35 & Strong & Moderate & 10 day/Shit in & 10 day/reduce injection \\
B5 & 477 & 6.31 & Weak & Moderate & 3 day/Shit in & No measures \\
B6 & 417 & 5.81 & Moderate & Slow & 3 day/Shit in & No measures \\
\hline
\end{tabular}

can be obtained. When the adjustment well is located in a high correlation area, the injection well needs more stringent adjustment measures, such as shutting in the well or reducing the injection rate for a long time. Otherwise, it can be considered to reduce the injection rate in a short time or take no measures.

A new method is developed to estimate injection-production correlation based on production data of injection-production wells. In the middle and late stage of oilfield development, only the injection and production rate cannot reflect the formation conditions, so the influence of production pressure and formation pressure should be considered. In the injection-production correlation analysis method, water injection index and liquid productivity index are introduced, and the correlation parameters of injection-production well are obtained by inverse calculation using the optimized calculation model and extended Kalman filter algorithm. The parameter and calculation process of this method is simple and has high accuracy, which is easy to be popularized in the field.

This method has been used for more than 20 adjustment wells in Bohai Oilfield, China. No dangerous situation occurred during the operation, and on the premise of ensuring the safety of the operation, a single adjustment well can be injected with more than $5000 \mathrm{~m}^{3}$ of water during the operation. This minimizes the impact of adjustment well drilling and completion operations on field development. It is proved that the method of accurate adjustment for high correlation wells is feasible, and the calculation method of injection-production correlation proposed in this paper has high accuracy, which should be popularized and used for reference in more oilfields.

\section{Appendix: Mathematical derivations}

Extended Kalman filter:

Nonlinear system model:
$\left\{\begin{array}{l}x_{k+1}=f_{k}\left(x_{k}\right)+H_{k}\left(x_{k}\right) E_{k} \\ v_{k}=g_{k}\left(x_{k}\right)+E_{k}\end{array}\right.$

Among,

$$
\begin{aligned}
\mathrm{E}\left(\xi_{k} \xi_{l}^{T}\right) & =Q_{k} \delta_{k l} \mathrm{E}\left(\eta_{k} \eta_{l}^{T}\right)=R_{k} \delta_{k l} \mathrm{E}\left(\xi_{k} \eta_{l}^{T}\right) \\
& =0 \mathrm{E}\left(\xi_{k} x_{0}^{T}\right)=0 \mathrm{E}\left(\eta_{k} x_{0}^{T}\right)=0
\end{aligned}
$$

Initial setting

$\hat{x}_{0}=\mathrm{E}\left(x_{0}\right) \hat{x}_{1 \mid 0}=f_{0}\left(\hat{x}_{0}\right)$

Applying equations $\widehat{x}_{\mathrm{k}}=\widehat{x}_{\mathrm{k} \mid k}$, for $\mathrm{k}=1,2, \ldots$, using predicted values in turn, can be obtained

$\widehat{x}_{\mathrm{k}+1 \mid k}=f_{k}\left(\widehat{x}_{k}\right)$

And,

$\left\{\begin{array}{l}x_{k+1}=A_{k} x_{k}+u_{k}+\Gamma_{k} \xi_{k} \\ w_{k}=C_{k} x_{k}+\eta_{k}\end{array}\right.$

Consider the linear Taylor approximation of $f_{k}\left(x_{k}\right)$ at $\hat{x}_{k}$ and the linear Taylor approximation of $g_{k}\left(x_{k}\right)$ at $\hat{x}_{k \mid k-1}$ :

$\left\{\begin{array}{l}f_{k}\left(x_{k}\right) \approx f_{k}\left(\hat{x}_{k}\right)+A_{k}\left(x_{k}-\hat{x}_{k}\right) \\ g_{k}\left(x_{k}\right) \approx g_{k}\left(\hat{x}_{k \mid k-1}\right)+C_{k}\left(x_{k}-\hat{x}_{k \mid k-1}\right)\end{array}\right.$

Among,

$A_{k}=\left[\frac{\partial f_{k}}{\partial x_{k}}\left(\hat{x}_{k}\right)\right] \quad C_{k}=\left[\frac{\partial g_{k}}{\partial x_{k}}\left(\hat{x}_{k \mid k-1}\right)\right]$

Here and thereafter, for any vector-valued function

$h\left(x_{k}\right)=\left[\begin{array}{c}h_{1}\left(x_{k}\right) \\ \vdots \\ h_{m}\left(x_{k}\right)\end{array}\right]$

Among,

$x_{k}=\left[\begin{array}{c}x_{k}^{1} \\ \vdots \\ x_{k}^{n}\end{array}\right]$ 
Then,

$$
\left[\frac{\partial h}{\partial x_{k}}\left(x_{k}^{*}\right)\right]=\left[\begin{array}{lll}
\frac{\partial h_{1}}{\partial x_{k}^{1}}\left(x_{k}^{*}\right) & \cdots & \frac{\partial h_{1}}{\partial x_{k}^{n}}\left(x_{k}^{*}\right) \\
\vdots & \ddots & \vdots \\
\frac{\partial h_{m}}{\partial x_{k}^{1}}\left(x_{k}^{*}\right) & \cdots & \frac{\partial h_{m}}{\partial x_{k}^{n}}\left(x_{k}^{*}\right)
\end{array}\right]
$$

And,

$$
\left\{\begin{array}{c}
u_{k}=f_{k}\left(\widehat{x}_{k}\right)-A_{k} \widehat{x}_{k} \\
\Gamma_{k}=H_{k}\left(\hat{x}_{k}\right) \\
w_{k}=v_{k}-g_{k}\left(\hat{x}_{k \mid k-1}\right)+C_{k} \widehat{x}_{k \mid k-1}
\end{array}\right.
$$

The corrected equations:

$$
\begin{aligned}
\hat{x}_{k} & =\hat{x}_{k \mid k-1}+G_{k}\left(w_{k}-C_{k} \hat{x}_{k \mid k-1}\right) \\
& =\hat{x}_{k \mid k-1}+G_{k}\left(\left(v_{k}-g_{k}\left(\hat{x}_{k \mid k-1}\right)+C_{k} \hat{x}_{k \mid k-1}\right)-C_{k} \hat{x}_{k \mid k-1}\right) \\
& =\hat{x}_{k \mid k-1}+G_{k}\left(v_{k}-g_{k}\left(\hat{x}_{k \mid k-1}\right)\right)
\end{aligned}
$$

The final filtering process is

$$
\left\{\begin{array}{l}
P_{0,0}=\operatorname{Var}\left(x_{0}\right) \\
\hat{x}_{0}=E\left(x_{0}\right) \\
P_{k, k-1}=\left[\frac{\partial f_{k-1}\left(\widehat{x}_{k-1}\right)}{\partial x_{k-1}}\right] P_{k-1, k-1}\left[\frac{\partial f_{k-1}\left(\widehat{x}_{k-1}\right)}{\partial x_{k-1}}\right]^{T}+H_{k-1}\left(\widehat{x}_{k-1}\right) C_{k-1} H_{k-1}^{T}\left(\widehat{x}_{k-1}\right) \\
\hat{x}_{k \mid k-1}=f_{k-1}\left(\widehat{x}_{k-1}\right) \\
G_{k}=P_{k, k-1}\left[\frac{\partial g_{k}\left(\hat{x}_{k \mid k-1}\right)}{\partial x_{k}}\right]^{T} \cdot\left[\left[\frac{\partial g_{k}\left(\hat{x}_{k \mid k-1}\right)}{\partial x_{k}}\right] P_{k, k-1}\left[\frac{\partial g_{k}\left(\hat{x}_{k \mid k-1}\right)}{\partial x_{k}}\right]^{T}+R_{k}\right]^{-1} \\
P_{k, k}=\left[I-G_{k}\left[\frac{\partial g_{k}\left(\hat{x}_{k \mid k-1}\right)}{\partial x_{k}}\right]\right] P_{k, k-1} \\
\widehat{x}_{k \mid k}=\widehat{x}_{k \mid k-1}+G_{k}\left(v_{k}-g_{k}\left(\widehat{x}_{k \mid k-1}\right)\right)
\end{array}\right.
$$

Funding The financial supported by the National Science and Technology Major Project of China (No. 2016ZX05058-002-003).

\section{Declarations}

Conflict of interest The author declares that there are no known competing financial interests or personal relationships that could have appeared to influence the work reported in this paper.

Ethical statement On behalf of all the co-authors, the corresponding author states that there are no ethical statements contained in the manuscripts.

Open Access This article is licensed under a Creative Commons Attribution 4.0 International License, which permits use, sharing, adaptation, distribution and reproduction in any medium or format, as long as you give appropriate credit to the original author(s) and the source, provide a link to the Creative Commons licence, and indicate if changes were made. The images or other third party material in this article are included in the article's Creative Commons licence, unless indicated otherwise in a credit line to the material. If material is not included in the article's Creative Commons licence and your intended use is not permitted by statutory regulation or exceeds the permitted use, you will need to obtain permission directly from the copyright holder. To view a copy of this licence, visit http://creativecommons.org/licenses/by/4.0/.

\section{References}

Feng QH, Zhang J, Wang S et al (2017) Unified relative permeability model and waterflooding type curves under different levels of water cut. J Petrol Sci Eng 154:204-216. https://doi.org/10. 1016/j.petrol.2017.04.031

Guo TK, Li YC, Ding Y et al (2018a) Evaluating of acid fracturing treatment in shale formation. Energy Fuels 31(10):1047910489. https://doi.org/10.1021/acs.energyfuels.7b01398

Guo TK, Tang SJ, Liu S et al (2018b) Physical simulation of hydraulic fracturing of large-sized tight sandstone outcrops. SPE J 26(1):372-393. https://doi.org/10.2118/204210-PA

Jiang W (2011) Research and practices of re-infill drilling technology for offshore close-spaced cluster-well pads. Nat Gas Ind 31(1):69-72. https://doi.org/10.3787/j.issn.1000-0976.2011. 01.015

Li YF, Sun W, He WW et al (2019) Prediction method of shale formation pressure based on pre-stack inversion. Lithol Reserv 31(1):113-121. https://doi.org/10.12108/yxyqc.20190113

Liu YS, Wang CJ (2003) Differential equation inversion method for automatically identifying permeability distribution of oil reservoir. Acta Petrolei Sinica 04:73-76. https://doi.org/10.3321/j. issn:0253-2697.2003.04.017

Liu FL, Mendel JM, Nejad AM (2009) Forecasting injector/producer relationships from production and injection rates using an extended Kalman filter. SPE J 14(04):653-664. https://doi. org/10.2118/110520-PA

Ma TS, Peng N, Chen P et al (2018) Study and verification of a physical simulation system for formation pressure testing while drilling. Geofluids. https://doi.org/10.1155/2018/1731605

Peng N, Ma TS, Chen P et al (2021) Pore pressure evaluation of formation testing while drilling under supercharged conditions. J Petrol Sci Eng 203:108689. https://doi.org/10.1016/j.petrol.2021.108689

Radwan AE, Abudeif AM, Attia MM et al (2019) Pore and fracture pressure modeling using direct and indirect methods in Badri Field, Gulf of Suez. Egypt J Afr Earth Sci 156:133-143. https:// doi.org/10.1016/j.jafrearsci.2019.04.015

Rui ZH, Li CC, Peng F et al (2017a) Development of industry metrics for offshore oil and gas projects. J Nat Gas Sci Engineering 39:44-53. https://doi.org/10.1016/j.jngse.2017.01.022

Rui ZH, Peng F, Ling KG et al (2017b) Investigation into the performance of oil and gas projects. J Nat Gas Sci Eng 38:12-20. https:// doi.org/10.1016/j.jngse.2016.11.049

Rui ZH, Cui KH, Wang XQ et al (2018a) A comprehensive investigation on the performance of oil and gas development in Nigeria: Technical and non-technical analyses. Energy 158:666-680. https://doi.org/10.1016/j.energy.2018.06.027

Rui ZH, Guo TK, Feng Q et al (2018b) Influence of Gravel on the propagation pattern of hydraulic fracture in the Glutenite Reservoir. J Petrol Sci Eng 165:627-639. https://doi.org/10.1016/j. petrol.2018.02.067

Vaferi B, Salimi V, Dehghan Baniani D et al (2012) Prediction of transient pressure response in the petroleum reservoirs using orthogonal collocation. J Petrol Sci Eng 98-99:156-163. https://doi.org/ 10.1016/j.petrol.2012.04.023

Wang GJ, Wang DM, Chen XB et al (2011) ECS well logging and its application in Xijiang Oilfield. J Oil Gas Technol 35(7):101-103. https://doi.org/10.3969/j.issn.1000-9752.2011.07.023 
Wang S, Qin CX, Feng QH et al (2021) A framework for predicting the production performance of unconventional resources using deep learning. Appl Energy 295:117016. https://doi.org/10.1016/j. apenergy.2021.117016

Xie XQ, Zhao H, Kang XD et al (2017) Prediction method of produced polymer concentration based on interwell connectivity. Pet Explor Dev 44(2):286-293. https://doi.org/10.1016/S18763804(17)30032-0

Xu SQ, Feng QH, Wang S et al (2018) Optimization of multistage fractured horizontal well in tight oil based on embedded discrete fracture model. Comput Chem Eng 117:291-308. https://doi.org/ 10.1016/j.compchemeng.2018.06.015

Yao YD, Li XF (2009) Dynamic and static methods for prediction and adjustment of well formation pressure. Oil Drill Technol 37(4):32-34. https://doi.org/10.3969/j.issn.1001-0890.2009.04. 008

Yao YD, Ge JL, Wei JZ (2001) Study on seepage law of low permeability reservoirs. Petrol Explor Dev 4:73-75+11-2. https://doi. org/10.3321/j.issn:1000-0747.2001.04.022

Yousef AA, Lake LW, Jensen JL (2006) Analysis and Interpretation of interwell connectivity from production and injection rate fluctuations using a capacitance model. Soc Petrol Eng. Society of Petroleum Engineers SPE-99998-MS. https://doi.org/10.2118/ 99998-MS
Zhang FJ, Luo XB, Liu YX et al (2011) Research on overall encryption adjustment technology of offshore oil field. Eng Sci 13(5):34-40. https://doi.org/10.3969/j.issn.1009-1742.2011.05.006

Zhao CS, Tao BZ (2008) Kalman filtering of linear system with colored noises. Geomat Inf Sci Wuhan Univers 33(2):180-182. https://doi. org/10.3969/j.issn.1671-8860.2007.10.009

Zhao H, Kang ZJ, Sun HT et al (2016) an interwell connectivity inversion model for waterflooded multilayer reservoirs. Petrol Explor Dev 43(1):106-114. https://doi.org/10.1016/S1876-3804(16) 30012-X

Zhao SW, Fan BT, Zhong LG et al (2017) Research and application of pressure prediction and control technology for infill adjustment wells during injection-production operations. China Offshore Oil Gas 29(1):99-104. https://doi.org/10.11935/j.issn.1673-1506. 2017.01.015

Zhu BL, Cheng YF, Xie XD (2011) Research and application of formation pressure prediction method for adjustment Wells. Complex Oil Gas Reserv 04(2):68-71. https://doi.org/10.3969/j.issn.16744667.2011.02.019

Publisher's Note Springer Nature remains neutral with regard to jurisdictional claims in published maps and institutional affiliations. 